\title{
LAS MUJERES BOLIVIANAS EN LAS CHACRAS, MALARGÜE, MENDOZA, ARGENTINA SU DOBLE CONDICIÓN DE MIGRANTE Y DE MUJER
}

María Milena Quiroz ${ }^{[1]}$

\section{Resumen}

Este estudio socioeducativo fue emprendido en la región de Las Chacras, Malargüe, Mendoza, Argentina. Ha tenido como centro de estudio la mujer de la comunidad con la descripción de sus prácticas, la construcción de sus significados y las formas de participación en su realidad microlocal. La mujer, desde el enfoque de esta investigación es considerada como ser relacional y vinculante con el mundo y los demás actores sociales. Así, se han explorado las características de las tensiones del modelo patriarcal sobre la posición y las relaciones de género. El estigma de ser representada por lo débil, privado, doméstico, pasivo, incompleto y asilado, se le ha excluido de la participación social, cultural y política.

Esta complejidad social contemporánea permite dilucidar la demanda y el deseo de la mujer por emprender nuevas identidades como grupo excluido en la sociedad civil y redefinir su reconocimiento de género como aquel que interviene en la cultura y en la educación de su entorno, con modos propios y particulares no impuestos.

Palabras claves: Mujer boliviana, mujer migrante, participación, género, identidades, comunidad.

\section{Summary}

This socioeducational study was undertaken in the region of Las Chacras, Malargüe, Mendoza and Argentina. It is focused on the women of the community and their practices, as well as the construction of its significances and different forms of participation in the micro-local reality. Based on the focus of this research, women are considered as a relational being that binds with the world and other social actors. Thus, we have explored the characteristics of the patriarchal model pressure upon gender relations. The stigma of women being represented as weak, domestic, passive, incomplete and isolated, has contributed to their exclusion from social, cultural and political participation.

[1] Licenciada en Ciencias de la Educación. Investigadora adscripta del Centro de investigación Interdisciplinar Filosofía y Escuela. (CIIFE). Profesora universitaria, Facultad de Filosofía y Letras. Universidad Nacional de Cuyo. E-mail: milena.quiroz@gmail.com 
This contemporary social complexity allows explaining the demand and the desire of women to undertake new identities as excluded group in the civil society and redefine gender's recognition taking into consideration its intervention on culture, as well as the education of the environment with their own particularity.

Keywords: Bolivian women, migrant women, participation, gender, identities, community.

\section{Introducción}

Esta investigación se enmarca dentro de la línea crítica social educativa y toma como referente metodológico la reflexión de la epistemología ampliada. Presenta como propósito describir y analizar la visión de mundo, la cultura, los significados, los sentidos y las tramas relacionales sociales que construyen las mujeres bolivianas de Las Chacras en su espacio popular.

Esta se elaboró durante 2011-2012 desde metodologías cualitativas con dos instancias. Una donde se efectuó observación participativa con entrevistas y encuentros y otra, de talleres de cine latinoamericano donde se abordaron algunos conflictos y problemáticas que afectan la vida de nuestros pueblos. La misma se propuso dilucidar los supuestos epistemológicos que acompañaron el trabajo de campo y las interpretaciones finales. Desde la epistemología ampliada no se puede hacer ciencia sin reflexionar acerca de ella y a la inversa. Así, esta actividad crítica configura todo el proceso de construcción del conocimiento de este proyecto.

Como estudio de género se rescata a la mujer boliviana como actor social que representa la otredad en la estructura simbólica. La idea es reconocer las características de las tensiones del modelo patriarcal sobre la posición y las relaciones asimétricas de género. Las mujeres de la comunidad traen consigo creencias arraigadas de división y barreras de clase, en nuevos entornos se someten a las mismas prácticas de división en su vida cotidiana, pero con beneficios "económicos", en comparación con sus posibilidades pasadas. Argentina, en particular es un país con fuertes tradiciones y matrices de división de género, de origen étnico y racial que la ubican y clasifican por debajo de los derechos sociales. Ellas se encuentran condicionadas por pautas y creencias culturales, tanto de su país de origen como el país receptor, en su actuar, pensar, educar y trabajar. Aun así, se considera que la mujer boliviana, en particular, a través de la migración ha logrado transformar prácticas que la reducían al espacio privado y se advierte su presencia con más fuerza en los espacios sociales. 
Muchos pensadores estudian la construcción de género en relación directa con la sexualidad de los hombres. Esta arista simboliza el marco de múltiples mecanismos de control en la sociedad burguesa moderna. Es así, que la construcción cultural de género en la historia se ha limitado a parámetros regulativos que definen cuáles son las prácticas normales y las anormales, las válidas y las no válidas, las posibles y las no correctas. Así, cuando se denuncia estas diferencias, se hace en cuanto a la diferencia de raza, de clase, de acceso a la cultura y a la educación no sólo ejercida por el hombre hacia las mujeres sino de las mujeres hacia las mujeres.

La mujer se estudia como un sujeto incompleto dentro de un modelo de pensamiento dominante antropocéntrico. Sin embargo, la mujer no es un ser fragmentario sino que sufre desigualdades e injusticias estructurales con respecto al hombre. Desde este punto de vista, la mujer no es en oposición al hombre ni este en oposición a ella. Es la posición diferencial en derechos en cuanto al hombre quien la motiva a resistir tal desigualdad. Estas batallas son externas, institucionales, simbólicas y discursivas frente a un modelo lineal de género que influye con su posición en el mundo.

\section{Revisión de la literatura}

La Población boliviana en el cinturón verde de Córdoba. Condiciones de vida e interacción con el medio natural es un estudio de López Gareri (1999), que trabaja la percepción sobre la migración boliviana en Córdoba. La estrategia inicial de desplazamiento, elaborada y ejecutada en los lugares de origen, en función de un proyecto individual y familiar específico, da lugar a una estrategia de adaptación al medio social y natural, a su vez condicionada por la posición que ocupan en el espacio de llegada y en particular por la posición que ocupan en el sistema productivo.

Migración, género y desigualdad social. La migración de mujeres bolivianas hacia Argentina es un estudio de Magliano María José (2009), que propone analizar los procesos de reproducción de desigualdades sociales en contextos migratorios a partir de la articulación de las dimensiones de género, etnia y clase social, centrando el estudio en la migración contemporánea de mujeres bolivianas hacia Argentina. Su estudio busca discutir como aquellas dimensiones condicionan las formas de inserción social y laboral de las mujeres migrantes en la sociedad de destino.

Las formas del narrar. Posibilidades y limitaciones de género en la construcción de trayectorias migratorias es una conferencia de Mallimaci Barral (2010), presentada en las Jornadas Nacionales de Historia de las Mujeres. Este trabajo muestra cómo los proyectos colectivos expresan y dan forma a lógicas familiares lo que no significa que no den cuenta de estrategias económicas de producción y reproducción. Por el contrario, lo familiar y lo económico se imbrican formando parte de una misma lógica económica. Resumiendo, las lógicas económicas que atraviesan la totalidad de los proyectos subyacen como motivación primaria del desplazamiento, el saber rutinizado contiene 
las formas y destinos en que las necesidades económicas se canalizan, y los mandatos sociales explican los sentidos posibles y limitados de convertirse en inmigrantes.

\section{Materiales y métodos}

Esta investigación se inscribió en los paradigmas interpretativo y crítico con una metodología cualitativa. Buscó describir e interpretar la trama de significados de la mujer en su entorno. Específicamente, buscó identificar y detallar la visión, la cultura, los esquemas significativos, los sentidos de las experiencias y las tramas relacionales sociales existentes de la mujer boliviana en la región.

A partir de la observación, las entrevistas y los talleres se elaboró una versión lo más textual posible. Se pidió grabar algunas instancias de diálogos y tomar fotografías. El registro fue por medio de notas de campo que respetaron las formas locales de expresión. En el proyecto participaron 20 familias de la región.

\section{Resultados y discusión}

La mujer de Las Chacras emprendió el proyecto de migración no sólo en busca de mejores condiciones económicas, sino también en busca de bienestar psicosocial, estabilidad, promoción personal y posibilidad de mejorar su vida y de sus familias. Su participación es crucial para comprender la construcción de este actor social histórico tan importante. El relato nos permite recuperar el anonimato sistémico de esta mujer boliviana tanto en el proceso migratorio como en la construcción y las relaciones de género.

La complejidad de la sociedad contemporánea nos permite dilucidar la demanda y el deseo de la mujer por emprender nuevas identidades como grupo excluido en la sociedad civil y comenzar a definir su reconocimiento de género que interviene en la cultura y la educación de su entorno. La pensadora Núbia Moreira $(2011)^{[2]}$ nos dice: "Enfrentar esa situación confusa en la relación de la distribución, o, más bien, la redistribución-reconocimiento, podemos aportar una pista para vencer las políticas de identidad".

La mujer busca, de forma consciente o inconsciente, recursos y apoyo para sus proyectos familiares, espacios donde desarrollarse, afectos, interés por conocer y crear su entorno. Particularmente, esta mujer diferente a la de su tierra busca ser reconocida como sujeto activo de su comunidad.

A nosotros nos descuentan el $5 \%$ y uno va a retirar los aportes y no hay nada. Nosotros vamos al hospital y nos cobran. Esta cooperativa se podría trabajar de diferente

[2] MOREIRA, NÚBIA (2011). La organización de las feministas negras en Brasil. Ed. Empresa gráfica de Bahía. Brasil. 


\section{GÉNERO E INDENTIDAD}

forma... Por ejemplo descontar la plata y pagarle un loteo a la municipalidad. Se podría. Yo lo hablé con Claudia eso y me dijo que no me convenía. Nosotros no podemos sacar una tarjeta.

Mujer de la comunidad.

Séptimo encuentro con la comunidad. 29 de Enero de 2012.

La información y el conocimiento que circula como dominante en la sociedad genera en ellas desconfianza. Esto posibilita una forma de resistencia y de denuncia. Significa la posibilidad de cambio dentro del hecho de advertir la estructura simbólica de las injusticias y establecer otras formas de prácticas desde su propio discurso, su voz.

Se puede imaginar, ellos tenían unos perros galgos. Nosotros necesitábamos plata y víveres para comer. Venía el hombre, traía unos trozos grandes de carne, al perro le daba unos trozos... y los chacareros mirábamos. El perro comiendo carne y nosotros no teníamos para comer...

Mujer de la comunidad. Séptimo encuentro con la comunidad. 29 de Enero de 2012.

En la Argentina, se han desarrollado estrategias y debates globales en estas últimas décadas para la implementación de políticas multiculturales. Se ha enfatizado en el reconocimiento y en la visibilidad de esta población en la sociedad frente a los procesos migratorios. María José Magliano (2009) ${ }^{[3]}$ nos dice:

Esta mayor visibilidad no supuso, sin embargo, variaciones en los procesos de exclusión, discriminación y marginación que constantemente ha afrontado este sector social en Argentina. La persistente estigmatización y desvalorización se reflejó en la construcción y reproducción de estereotipos respecto a estos 'otros', asociada a conductas, a comportamientos y a costumbres que han justificado el desarrollo de aquellos procesos.

Frente a esto, la mujer es la principal impulsadora de la ruptura de estas categorías históricas que la clasifican como lo segundo, no sólo por su género, sino también por su raza, etnia y clase.

Arturo Roig en su texto Teoría y Crítica del Pensamiento Latinoamericano da cuenta de la emergencia en cuanto a pensar la posibilidad de un nuevo sujeto histórico. Este nuevo actor social que se requiere para la región debe estar en constante autoproducción, haciéndose subjetivamente, en relación con la construcción de un espacio histórico diferente. Con un carácter regional, se deslumbra que este hombre: "sea

[3] MAGLIANO, M.J. (2009). Migración, género y desigualdad social. La migración de mujeres bolivianas hacia Argentina. Revista Estudios Feministas, Centro de Filosofía e Ciencias Humanas, Universidad Federal de Santa Catarina. vol. 17, núm. 2. Florianópolis. Brasil. 
tenido como valioso al conocerse por sí mismo" como plural, en cuanto que las categorías de "mundo" y de "pueblo" hacen referencia justamente en él a una universalidad sólo posible desde una pluralidad, motivo por el cual el autor nos enuncia un a priori antropológico, como categoría de pensamiento.

Arturo Roig (2004) ${ }^{[4]}$ nos dice:

Desde lo normativo y las pautas que lo expresan se nos presentan como esencialmente constitutivos de la forma que hemos de darnos para poder realizar la vida, conformación que hemos de alcanzar, en este caso, para ejercer la filosofía, en otros términos, para podernos constituir o no como sujeto filosofante dentro de los límites posibles de autenticidad. En efecto, si una de las pautas nos conmina a partir de nosotros mismos como valiosos, esa autovaloración determina la producción y la conforma orgánicamente.

Pensarse y revalorizarse en la historia y en los hechos prácticos que nos acontecen como mujeres implica enfrentar la dualidad de afirmarse o negarse, ser visible o invisible, estar presente o escindido. Este problema sobre el humanismo latinoamericano implica advertir lo doloroso que es estar afuera del interés general.

El sistema vigente, desde algunas aristas, hace uso de las vulnerabilidades de los diferentes espacios sociales y nutre su propio "modelo". Lo que genera desarrollo desigual, estructuras regionales dominantes y discursos hegemónicos. Esta violencia material y simbólica sistémica es discontinua, por lo cual admite cambios que comienzan en las propias representaciones personales frente a estas "imposiciones".

Esta mujer, en general, no depende económicamente de su marido; en muchos casos este es su compañero de trabajo y de proyectos familiares. Aun así, el patriarcado y la imposición de jerarquías la atraviesa no sólo a ella sino a la comunidad en general.

Esta colectividad realiza múltiples aportes económicos, sociales y culturales a la Argentina, por lo que no se debe excluir ni considerar esta población como segregada de todo derecho. Es la propia comunidad malargüina la que debe solidarizarse y apoyar los procesos de esta, en especial de las mujeres.

Así, frente a estructuras rígidas de exclusión que no admiten ni dan lugar a la participación social de algunos sectores representados como otredad, hablamos de un nuevo humanismo como fuente de cambio. Es en el mundo de las ideas, el pensamiento

[4] ROIG. Arturo (2004). Teoría y crítica del pensamiento latinoamericano. Edición a cargo de Marisa Muñoz, con la colaboración de Pablo E. Boggia. La presente edición digital, actualizada por el autor, se basa en la primera edición del libro (México: Fondo de Cultura Económica, 1981) y fue autorizada por el autor para Proyecto Ensayo Hispánico y preparada por José Luis GómezMartínez. En: http://www.ensayistas.org/filosofos/argentina/roig/teoria/ 
donde se producen las grandes transformaciones humanas que luego influyen en los aparatos económicos y políticos.

$$
\begin{array}{r}
\text { Que nunca me falte nada (risas). } \\
\text { Cuando no me falta algo, me falta otra cosa... Siempre hay una urgencia. } \\
\text { Mujer de la comunidad. }
\end{array}
$$

Quinto Encuentro con las mujeres. 23 de Enero de 2012.

Altos son los costos personales, emocionales y vinculares que pagan las mujeres producto de la reproducción de ideologías dominantes. Cierta continuidad de su posición de género y su vulnerabilidad representan las regularidades de nuestra sociedad ya que a nadie le conmueve nada.

Consideramos un desafío estudiar la indiferencia histórica hacia las injusticias y el poder simbólico de las lógicas imperiales, la falta de consciencia política sobre las relaciones y el desarrollo crudo del capitalismo.

En cuanto a la dimensión de género como estudio, consideramos que no sólo es un complemento que enriquece la comprensión de ciertos fenómenos, sino que construye un elemento de aporte para las relaciones sociales. La descripción de los acontecimientos simboliza dejar al descubierto al ser humano y mostrar su condición histórica.

\section{Conclusiones}

Escribir y hablar sobre América Latina implica posicionarse, analizar todas las aristas dentro de las relaciones de poder y comprender el lugar que se nos ha otorgado como región del subdesarrollo del gran aparato capitalista. Eduardo Galeano $(1991)^{[5]}$ sostiene que:

uno escribe para despistar a la muerte y estrangular los fantasmas que por dentro lo acosan, pero lo que uno escribe puede ser históricamente útil sólo cuando de alguna manera coincide con la necesidad colectiva de conquistar la identidad. Esto, creo, quisiera uno, que al decir: 'Así soy' y ofrecerse, el escritor pudiera ayudar a muchos a tomar consciencia de lo que son.

La identidad latinoamericana surge a partir del reconocimiento de un ser diferente, de un hombre atravesado e interpelado por la colonización y por su pasado ancestral borrado y casi anulado. La clasificación occidental cultural y económica demarcó lugares de producción donde se delimitó, en especial, a la mujer a un lugar de inferioridad.

[5] GALEANO.E. (1991). Memorias del fuego. Ed. Siglo XXI. Madrid. España. p.73. 
La mujer boliviana por su piel, identidad étnica, condición y color ocupa lugares degradantes en nuestra sociedad. Fue quizás, la sobrevalorización hacia las prácticas europeas que generó exclusión y categorización en nuestro continente y recién hoy, en la historia, este modelo perfecto antropocéntrico cae junto con los grandes sueños planteados por estos imperios.

Estructuralmente y desde la hipocresía cultural se puede silenciar y correr a la mujer migrante boliviana de la historia oficial, marcarla como la otredad y con ello hacer uso legítimo de ella para su explotación, ninguneo y opresión, se puede pasar esta clasificación social como natural en el discurso social y convertir la pobreza en un proceso normal.

Por ello, este estudio intenta manifestar y revelar el dolor, el padecimiento y las carencias de esta población inserta en dicho aparato. Si bien, estas mujeres encuentran formas de resistencia en múltiples signos de expresión cultural como la danza, el debate, la educación y el relato diario advertimos que es intolerable la condición inferior de bloqueo de desarrollo.

La mujer toma consciencia de su ubicación estructural pero no siente ningún tipo de identificación y reconocimiento con ello. Así, advertimos que es preciso un espacio de organización política y educativa con asesoramiento específico para la formación de sus dirigentes. Dada la vulnerabilidad de la población, por sus carencias, es central el apoyo y acompañamiento de la comunidad educativa en sus prácticas organizativas hacia objetivos comunes emancipadores.

La organización política de estas mujeres será el puente que les permita luchar en espacios concretos gubernamentales. El relato, la denuncia, la voz de ellas simboliza los primeros sonidos en los cuales se acentuará una futura formación política que les permita caminar hacia la concretización de sus derechos. Dicho trayecto les permitirá correrse del lugar subordinado patriarcal y ser parte de la construcción de una historia mejor para sus hijos.

Aun así, abrimos más interrogantes y nos preguntamos: ¿Desde cuándo es tan tolerable el dolor y la injusticia ajena por parte de la sociedad?, ¿Hasta cuándo las matrices coloniales circularán en la historia oriental para desacreditar lo propio? ¿Por qué se aprende tan poco de procesos tan dolorosos como la violación de los derechos obligatorios de los seres humanos?, ¿Por qué no existe ninguna forma de solidaridad frente a estas mujeres negadas en la región? ¿Por qué no se siente vergüenza de lo que acontece? ¿Por qué no genera nada esta mujer vulnerable?

Mujeres que denotan cultura en movimiento, una maternidad trasnacional desde la lucha y la resistencia por la reivindicación ante la discriminación y la xenofobia social, mujeres que enfrentan la negociación filiar de poder con el hombre en su hogar y en 
la comunidad en general, buscan redefinir sus roles y funciones en el espacio. Esta mujer, lejos de ser pasiva, es uno de los pilares no sólo de la migración en sí sino del desarrollo familiar a posteriori en el nuevo contexto. Es un nuevo actor, que siempre estuvo pero ahora es visible.

Invisible, anónima, subestimada y víctima, mujer boliviana que transita el silencio, la lejanía en el tiempo, la soledad y la posibilidad de encontrarse por la nada, por nada y por nadie. Dentro de la montaña grita, canta y relata. La pasión en sus manos está puesta en la tierra, la siembra, la crianza y el sol. Piel oscura, quemada, ojos bajos que miran el camino y nunca el oriente del destino, olor a cultura Quechua y Aimara que sangra junto a la historia. Vienen tiempos mejores, vienen nuevos tiempos, viene su tiempo mujer andina.

María Milena Quiroz. 2012.

\section{Lista de referencias}

Galeano, Eduardo (2003). Las venas abiertas de América Latina. Editorial Catálogos S.R.L. Argentina.

López Gareri V. (1999). Población boliviana en el cinturón verde de córdoba. Condiciones de vida e interacción con el medio natural. Centro de Estudios Avanzados de la Universidad Nacional de Córdoba y el Laboratoire Population Environnement/ ORSTOM y la Université de Provence, Marsella, Francia. Red de estudios de población ALFAPOP. Córdoba. Argentina.

Magliano, M.J. (2008). Migración de mujeres bolivianas hacia Argentina: cambios y continuidades de género. Amérique Latine Histoire et Mémoire. Les Cahiers ALHIM. Argentina.

Magliano, M.J. (2009). Migración, género y desigualdad social. La migración de mujeres bolivianas hacia Argentina. Revista Estudios Feministas, Centro de Filosofía e Ciencias Humanas, Universidad Federal de Santa Catarina. vol. 17, núm. 2. Florianópolis. Brasil.

Mallimaci Barral, Ana (2010. Septiembre). Las formas del narrar. Posibilidades y limitaciones de género en la construcción de trayectorias migratorias. Documento presentado en: X Jornadas Nacionales de Historia de las Mujeres y V Congreso Iberoamericano de Estudios de Género: "Mujeres y género: poder y política". Universidad Nacional de Lujan. Argentina. 
Moreira, Núbia (2011). La organización de las feministas negras en Brasil. Ed. Empresa grafica de Bahía. Brasil.

Roig. Arturo (2004). Teoría y crítica del pensamiento latinoamericano. Edición a cargo de Marisa Muñoz, con la colaboración de Pablo E. Boggia. La presente edición digital, actualizada por el autor, se basa en la primera edición del libro (México: Fondo de Cultura Económica, 1981) y fue autorizada por el autor para Proyecto Ensayo Hispánico y preparada por José Luis Gómez-Martínez. En: http:// www.ensayistas.org/filosofos/argentina/roig/teoria/ 